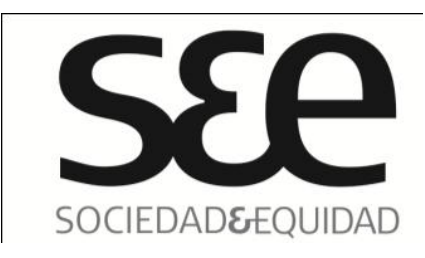

\title{
Discursos sobre corrupción en México
}

\author{
Discourses about corruption in Mexico
}

$\begin{array}{ll}\text { Nombre: } & \text { Fernando Gil Villa (1) } \\ \text { Filiación: } & \text { Universidad de Salamanca } \\ \text { País: } & \text { España } \\ \text { Correo: } & \text { gilvi@usal.es }\end{array}$

\section{Resumen}

Gobernantes, intelectuales y medios de comunicación, tienden a definir la corrupción como un concepto extraordinario, actual, público y económico. Por otra parte, la comparación con el cáncer y la asociación indiscriminada con otros problemas sociales, especialmente la pobreza y la inseguridad, permite extraer de los discursos un mensaje final pesimista que exigiría un cambio social radical. Sin embargo, la ciudadanía parece inclinarse por una concepción opuesta en la que la corrupción es el estado normal de los sistemas individuales y sociales. El análisis del sentido del humor popular permite entrever una operación, compatible con la cultura nihilista de la alta modernidad, por medio de la cual se extrae en varios sentidos lo positivo de lo negativo, se neutraliza la tensión social $y$, al mismo tiempo, se dota de contenido rupturista a la función social de la corrupción.

\section{Palabras Claves}

Corrupción, Opinión pública, Análisis del discurso, Nihilismo, Función social.

\footnotetext{
${ }^{1}$ El autor es Sociólogo, académico del departamento de Sociología de la Universidad de Salamanca, España. Además es profesor Visitante de la Universidad de Chile 2012. Sus líneas de investigación son: sociología de la educación y sociología de la desviación.
} 


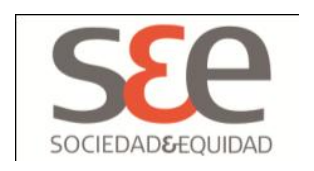

\begin{abstract}
Rulers, intellectuals and media tend to define corruption as a unique, modern, public and economic concept. Moreover, the comparison with cancer and the indiscriminate association with other social problems, especially poverty and insecurity, can lead us to extract a pessimist final message from these discourses, requiring a radical social change. However, citizens seem to incline towards the opposite view where corruption is considered the normal state of individual and social systems. An analysis of the popular sense of humour allows us to glimpse an operation, compatible with the nihilist culture of high modernity, through which the positive is taken out from the negative in many ways, social tension is neutralized and, and at the same time, corruption is endowed with a groundbreaking social function.
\end{abstract}

\title{
Keywords
}

Corruption, Public opinion, Discourse analysis, Nihilism, Social function.

\section{La corrupción como cáncer de la sociedad mexicana}

En la evolución del Índice de Percepción de la Corrupción elaborado por Transparencia Internacional en la década 2002-2012, México pasa del puesto número 57 al 105, con un puntaje de 3.6 y 34, para los dos años del continuo, señalado y siendo 0 la situación máxima de corrupción percibida en una escala que va hasta el 10 o, para el último informe, correspondiente al año 2012, hasta el 100. En ese intervalo, los países que se mantienen por debajo de México en América Latina, por poner un referente territorial regional que permita situar un contexto inmediato, son cinco: Honduras, Guatemala, Venezuela, Ecuador y República Dominicana. En el otro extremo tenemos a Chile, que en el año 2002 ocupaba el lugar 17 de la lista, con 7.5 puntos -trece puestos por encima del segundo, Uruguay, y tres por encima de España-, y en el año 2012 compartía con Uruguay el puesto 20, con 72 puntos - diez por encima de España-. Debido a este continuo descenso, no es extraño que la prensa escrita con mayor tirada se incline por titulares contundentes en los últimos años. Así, refiriéndose al informe del 


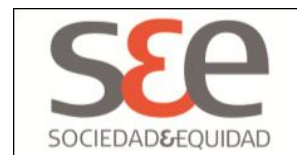

2010 del susodicho organismo internacional, se podía leer el 27 de octubre del mismo año en El Universal ${ }^{2}$ : «México, menos democrático» y «más corrupto».

Frecuentemente, los medios de comunicación airean datos estadísticos extraídos de informes y estudios en los que se ofrece una imagen del país claramente negativa. El impacto en la audiencia es directamente proporcional a la notoriedad social de los afectados en los distintos niveles: territorial, local, regional y nacional. Un segundo criterio, pensando siempre en el mismo objetivo de productividad en términos de audiencia, es que prima lo personal frente a lo corporativo, salvo cuando la noticia permita la personalización fácil en la interpretación -el $77 \%$ de las empresas mexicanas confiesan haber tenido un fraude en el último año (KPMG, 2009:4) 3 $^{3}$ El impacto también aumenta cuanto mayor es la cantidad económica objeto de la práctica denunciada. Es bien conocido el importante papel etiquetador de los medios en la percepción de los actos criminales por parte de los ciudadanos (Reiner, 1997: 211). En el caso de la corrupción, parece realizarse difundiendo una concepción reduccionista del problema: se trataría, sobre todo, de una cuestión pública más que privada, de grandes magnitudes y de fácil traducción económica.

Pero los medios de comunicación no construyen la realidad social de la corrupción únicamente definiéndola de una determinada forma. Ésta sería, en todo caso, una dimensión pasiva que se complementa con otra activa de la que emana un mensaje catastrofista: la corrupción está tan extendida en el cuerpo social y es tan letal, que tanto la democracia como el orden social están amenazados. El corolario parece evidente: la única vía para prevenir la corrupción pasa por alterar inmediata y radicalmente el estilo de vida.

Los medios de comunicación no son, sin embargo, los únicos responsables en la modelación de ideas y creencias sobre las que se establece la percepción de un problema social. Su labor socializadora, independientemente del resultado final -que no será muy eficaz en la interpretación conflictualista que en este artículo se hará-, es más o menos compatible con los mensajes emitidos por otros dos creadores legítimos de opinión: gobernantes y expertos. Para nuestros propósitos, es necesario averiguar si existe un grado interesante de compatibilidad, si el impulso formador, en el sentido de inculcación de ideas directas e indirectas explicativas del fenómeno de la corrupción, empuja en la misma dirección en los

2. http://www.eluniversal.com.mx/notas/719227.html

3. La Encuesta de Fraude y Corrupción en México de 2008, realizada por la empresa KPGM, se basó en una encuesta a 235 directivos que operaban en la época en México en distintos sectores y cuyos ingresos oscilaban entre 200 y 5000 millones de pesos. 


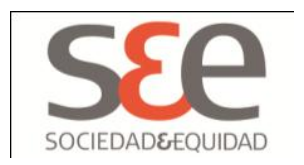

tres casos mencionados, potenciando la lectura negativa. A continuación expondré algunos ejemplos que permiten avalar, provisionalmente, una respuesta positiva a esa cuestión central, hipótesis necesaria para desarrollar la segunda parte de nuestra reflexión y ofrecer una conclusión sobre la función social de la corrupción.

En su ensayo «Reflexiones sobre la corrupción en México», el profesor de la UNAM, Tomasini Bassols, observa que «es una ingenuidad pensar que una enfermedad social como la corrupción podría perdurar indefinidamente sin acabar con el paciente, es decir (en este caso), con la nación mexicana» (Tomasini Bassols, 2009: 251). El recurso a la metáfora del cáncer para expresar la gravedad de un problema social se basa en los prejuicios que siembran opinión pública sobre el referente. En teoría, han debido disminuir en las últimas décadas, a medida que la enfermedad se ha extendido. Sin embargo, la información que se maneja sigue siendo en muchos casos errónea. Pese a los progresos en el tratamiento del cáncer -escribía Susan Sontag en los años setenta-, mucha gente sigue creyendo en la ecuación cáncer $=$ muerte $($ Sontag, 2008: 29). Varias décadas después, esa frase podría reescribirse sin muchos problemas, dado que una buena parte de la población continúa realizando aquella asociación negativa ${ }^{4}$. Periodistas y políticos siguen abundando en la comparación con el cáncer. Asimismo, la corrupción puede ser asociada también a una entelequia de carácter fantasmagórico. En el primer párrafo del artículo «La lucha contra la corrupción en México», de Guillermo Haro Bélchez, visible a finales de 2010 en la web del Centro Latinoamericano de Administración para el Desarrollo, se lee: «Hay prácticamente un consenso de que el mayor de los fantasmas que recorre el mundo en este final de siglo es el de la corrupción» ${ }^{5}$.

¿Qué relación guardan ambas metáforas? En principio, el cáncer aparece pintado en ocasiones como un fantasma, dado su supuesto carácter terrorífico. «Hoy el cáncer está al servicio de una visión simplista del mundo, que puede volverse paranoica», consideraba Sontag (Ibíd.: 83). De ahí, abundaba esta autora, que el cáncer se viva a menudo como una forma de posesión demoníaca que lleve al enfermo, en algunos casos, a recavar el auxilio exorcista de los curanderos. Ahora bien, quien posee, ¿no es siempre un fantasma, cual la muerte misma, cuya

4. Considérense estos datos extraídos de una encuesta a la población castellano-leonesa, en España, en el año 2010: el 71,9\% teme al cáncer más que a cualquier otra enfermedad; cerca de un tercio considera que es incurable o mortal; un 20,7\% opina que nunca se llegará a acabar con ella, y un $67,3 \%$ que ese objetivo se logrará sólo en un futuro lejano (Encuesta inédita, parte del proyecto de investigación, Cáncer y exclusión social, dirigido por el autor del artículo, en fase de desarrollo. Ficha técnica: población de Castilla y León de 18 y más años; tamaño de la muestra: 401 individuos; muestreo polietápico; error: +/- $5 \%$ ).

5. http://www.clad.org/documentos/otros-documentos/la-lucha-contra-la-corrupcion-en-mexico. 


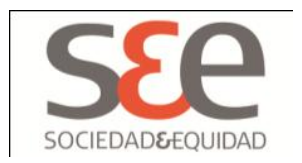

imagen asoma en el cuerpo que se corrompe? Es por tanto la calidad fantasmagórica de la corrupción la que permite usar el concepto en los discursos de forma negativa, activando el miedo a la muerte en el imaginario colectivo.

\section{Inseguridad y pobreza como metástasis del cáncer de la corrupción}

Si pasamos ahora a analizar los discursos de los gobernantes, llegaremos a la misma conclusión. En el Manual Ciudadano 2011, editado por la Secretaría de Desarrollo Social (SEDESOL, 2010: 10), vemos que el objetivo enunciado es disminuir la pobreza, la corrupción y la inseguridad. La primera cuestión que aquí se plantea, es doble: ¿por qué se consideran de forma conjunta? y ¿qué tipo de relaciones guardan entre sí los tres términos mencionados? Puesto que la respuesta no es explícita, debemos pensar que tal omisión tiene ya un significado. Siguiendo el guión fenomenológico a la hora de interpretarlo, teniendo en cuenta, por lo tanto, las creencias y opiniones sobre la corrupción que maneja en estos momentos la opinión pública mexicana, necesarias para desvelar el saber ingenuo que marca la realidad que los autores del informe dan por sentado, podemos intentar reconstruir el razonamiento partiendo de las altas tasas de desigualdad social, inseguridad y corrupción, presentadas por los informes internacionales. Una alta desigualdad explicaría comportamientos corruptos, pero también podría pensarse al revés, que la corrupción genera desigualdad e inseguridad. Si ahora intentamos hacer compatibles esta última forma de la ecuación con la metáfora del cáncer, tendremos que el mal nefasto y endémico de la corrupción se extiende por el cuerpo social como una metástasis, generando otros males como la inseguridad y la desigualdad. Ahora bien, si no hay vacuna contra el factor básico y causal de la corrupción -igual que no la hay contra el cáncer en general-, acabar con la pobreza y la inseguridad es misión prácticamente imposible. A favor de la conclusión de signo pesimista jugaría la impotencia de los gobernantes, en su intento de detener la sangría de muertes en la lucha contra el crimen organizado, algo especialmente evidente durante la presidencia de Felipe Calderón.

La metáfora militar, nos recordaba Sontag, comenzó a utilizarse en medicina alrededor de 1880 , con la aparición de las bacterias como agentes patógenos. No se lograría sin embargo su pleno rendimiento hasta un siglo después, cuando podía afirmarse que «la enfermedad se convierte en el enemigo contra el que la sociedad entera debe alzarse en pie de guerra» (Sontag, 2008: 80). Los «partes» difundidos en la contienda por los médicos eran, a finales de los años setenta, pesimistas, pese a los progresos de la entonces incipiente quimioterapia e inmunoterapia (Ibidem). Curiosamente, hoy en día, la lectura de la retórica imperante apunta en la misma dirección, a pesar de los avances y aunque se aloje en otro nivel lógico. El cáncer se concibe ahora como algo «inherente a la 


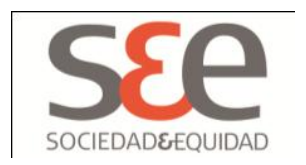

condición humana y por tanto imposible de ser erradicado completamente» (Germà Lluch, 2009: 81). De la misma forma, el uso de la jerga militar para explicar la corrupción como una enfermedad grave que aqueja a la sociedad mexicana prevalece sobre el de la retórica humanitaria, para la cual el paciente tendría que ser tratado con cierta comprensión y optimismo. El efecto paradójicamente nocivo -la consecuencia no procurada- del mensaje emitido por gobernantes y expertos, es pues el mismo que causa el etiquetado del enfermo: la identificación con el rol de enfermo obstaculiza la curación.

Las teorías del etiquetado, tal y como las estudia la sociología de la desviación, y que podríamos aplicar en nuestro caso a la corrupción, muestran cómo el rótulo de corrupto podría suponer, para el individuo o para la sociedad a la que se aplica, la generalización de rasgos que conforman un carácter coherente y sancionado negativamente por la cultura (Gil Villa, 2007: 45). La corrupción atrae así connotaciones de inseguridad y de pobreza, como si estas últimas fueran metástasis de la primera. Los tres conceptos son, sin embargo, claramente independientes, y sólo desde la sociología espontánea pueden mezclarse en el acto irracional, de efectos discriminatorios, que supone el rotulaje.

Un análisis de la situación basado en la lógica, por el contrario, debería sacar a la luz ciertos aspectos fundamentales en la reflexión sobre la corrupción en México. En primer lugar, la inseguridad, uno de los aparentes motores de la corrupción. Se olvida que la tasa de homicidios ha bajado desde 1997, o que la tasa de Washington D. C. es el triple que la de Ciudad de México. Lo cierto es que la probabilidad de toparse con una muerte violenta para un mexicano es menor hoy que hace diez años ${ }^{6}$. La tasa de homicidios de México a nivel nacional en 2010 es de 20 por 100.000 habitantes, de acuerdo si la fuente son las estadísticas sanitarias, y algo menos si se consideran los datos de la justicia criminal, por debajo de países como Venezuela, Colombia, Trinidad, Tobago, Brasil, Guatemala, Jamaica o El Salvador, en la región (UNODC, 2011: 23). Tampoco debe confundirse la delincuencia en general con el crimen organizado. Los medios de comunicación pueden ofrecer una impresión falsa de la realidad al dedicar la mayor parte del tiempo a los delitos de sangre violentos. En realidad éstos ocupan una mínima parte del total de las infracciones a la ley. De igual manera, la mayoría de las víctimas que arrastra el crimen organizado están implicadas en los negocios ilegales por cuyo monopolio luchan.

\footnotetext{
${ }^{6}$.http://www.ahorasi.com/a-pesar-del-combate-contra-el-narcotrafico-disminuye-la-tasa-dehomicidios-en-mexico/
} 


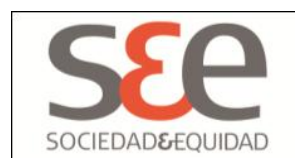

En segundo lugar, la ausencia o la escasez de corrupción no garantizan la igualdad social. Teóricamente es posible una sociedad en la que la obediencia a las normas vigentes, la honestidad y la solidaridad, se den en un alto grado, y sin embargo se observe una distribución desigual del poder político y de los recursos. Ella causada por factores ajenos al esfuerzo y al mérito individual. Con esto no se pretende negar situaciones históricas, algunas de ellas actuales, en las que coincide un alto grado de desigualdad con un alto grado de corrupción. Únicamente se pretende señalar que la relación entre las dos variables no es necesaria ni sencilla. Incluso si colocamos la reflexión no tanto en el terreno teórico sino en el de la observación práctica, podemos encontrar casos que avalan la necesidad de expresar con cuidado esa relación. En América Latina tal y como se expuso al principio de este trabajo, Chile posee la puntuación más baja en el Índice de Percepción de Corrupción, por debajo incluso de países europeos como España. Y sin embargo, al mismo tiempo, en el capítulo de ingresos del Informe de la OCDE Society at a Glance, de 2011, aparece situado como el país de la OCDE con mayor desigualdad, con un coeficiente de Gini de 0,50 , siendo el promedio de 0,31. (OCDE, 2011:67).

Es cierto que el sistema social mexicano es injusto en el sentido de que funciona con una doble estructura, legal y para-legal. "No se puede afirmar que el derecho no exista -escribe un analista mexicano de la desigualdad-, o que en el extremo no exista el Estado de derecho; existe, sí, pero está lleno de excepciones, de lagunas, temporales y espaciales, en que la relación se rige por otro tipo de normas contrarias u opuestas al derecho racional establecido; se trata de la negociación al margen de la ley, el favor, las clientelas, la impunidad, la corrupción, el influyentismo, todos son términos que denotan esas excepciones que se dan día con día» (Durand Ponte, 2010: 75). En la práctica, esto supone que «un particular que quiera tramitar cualquier asunto, desde una solicitud de trabajo hasta la obtención de un acta de defunción, tiene ante sí dos caminos: realizar el trámite por la vía legal, o recurrir a sus contactos» (Dehesa, 2002: 44). Pero llegados a este punto, lo que normalmente encontramos son análisis que se dedican a criticar de inmediato, por principio, a este sistema social dual al que aludimos de forma simplificada con el término corrupción. El sesgo general es, pues, coherente con el clima de negativismo cultural que poco a poco iremos pintando en este texto. Las interpretaciones autorizadas de la corrupción se fijan en lo negativo, no en lo positivo, entendiendo por tal el funcionamiento pacífico del sistema social. Lo que tenemos es una inversión de la realidad paralela a la que hacen los medios pero en un nivel más profundo. La corrupción es el estado normal, y ello tanto en un ser biológico como en un ser humano dotado de capacidad moral. Sólo los santos muestran almas e incluso, según el mito, cuerpos 


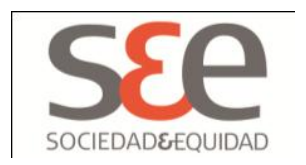

incorruptibles. Ellos constituyen, sin embargo, una clara excepción en nuestra especie. Lo mismo ocurre con las sociedades. El estado normal en ellas es cierta corrupción. $Y$ sin embargo, no es este el punto de vista que ofrecen algunos de los más renombrados historiadores mexicanos. Para ellos, la corrupción es un proceso histórico reciente, un fenómeno moderno ligado a los técnicos y burócratas con traje y corbata (Krauze, 1996: 162). El problema que observamos en este planteamiento puede disculparse como un sesgo inconsciente derivado de la deformación profesional del historiador, por el cual todo pasado fue mejor. Así, Iturbide y Santa Anna derrocharon o hicieron negocios turbios, Porfirio pudo beneficiase de su posición, pero ninguno de ellos, ni siquiera ninguno de los militares revolucionarios que arruinaron bancos con sus créditos, eran realmente ejemplos de corrupción, porque no eran exactamente materialistas, o porque los actos de aprovechamiento personal estaban compensados por su honor, su amor a la gloria o su paternalista sentido del Estado. Esta interpretación no se sostiene desde el punto de vista lógico. Si en vez de decenas de generales que adquirieron fincas durante la Revolución, hubiera habido miles, miles se hubieran beneficiado. Si las corruptelas de los funcionarios de hoy son cuantitativamente mayores es sólo porque más personas pueden aprovecharse del erario público. En cuanto a la diferencia cualitativa, es cierto que los políticos de nuestros días carecen de ideales mesiánicos, pero ningún valor justifica el beneficio propio a costa de los demás.

Queda aclarado así una parte del sesgo negativista del concepto de la corrupción. Gracias a él se obstaculiza, en la opinión pública, la visión completa y compleja de la misma. El objetivo de luchar contra la corrupción no puede realizarse a través de visiones parciales que demonicen una época, que hagan sentir a los ciudadanos de una sociedad en un momento dado, personajes de un cuento en el que son mucho más víctimas o culpables -según se mire al terreno del los políticos a al de toda la sociedad- que otros pueblos o sus antepasados. La estrategia informativa etiquetadora y traumatizante no sólo ayuda poco sino que falta a la verdad.

Pero lo que también se logra es ahorrar la tarea de rastrear el complejo proceso por el cual la ciudadanía procesa la información y toma una decisión al respecto. Porque se suele dar por supuesto que la corrupción es un comportamiento que la estructura impone al actor social. Resta pues, desvelar en la medida de lo posible dicho proceso. Partiremos de la base de que se realiza de forma espontánea, indirecta y relativamente sometida al control de la conciencia social, pero funcional y visible, así como coherente a la luz del análisis social, obedeciendo a tendencias culturales profundas. 


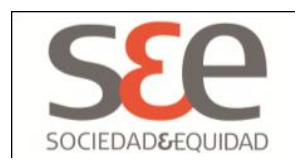

\section{El telón cultural de fondo: nihilismo y negativismo}

Para ello conviene que centremos la observación en el concepto del negativismo. La argumentación que nos servirá de guía, yendo de lo general a lo concreto, debería ser una referencia obligada, aunque simplificada, dado el espacio disponible en este artículo, a la socialización en el nihilismo, como matriz del negativismo. En principio, debería ser suficiente para nuestros propósitos llamar la atención sobre la potente crítica de la cultura que se va intensificando a lo largo del siglo XX, con el desarrollo del pensamiento nietzschiano bajo la batuta de la filosofía de la sospecha, el post estructuralismo y los debates anexos sobre la crisis de la modernidad y sus «promesas», con su traducción sociopolítica en la debilitación de las ideologías y el aumento de la desafección política, por un lado, y la desacralización de la ciencia y la cultura por otro ${ }^{7}$. La deconstrucción de los principios y valores subyacentes de la cultura occidental moderna abonan el terreno para una época de transición caracterizada por la evaluación constante en todas las esferas, lo que en términos metafóricos podría también expresarse como un período regido por el signo de lo negativo.

Para dar un paso en la concreción de esta idea, me serviré de una interpretación ad hoc de la obra de Niklas Luhmann. Esta constituye uno de los intentos más ambiciosos por crear un sistema teórico de pensamiento de amplia difusión e influencia más allá de la sociología, especialmente en el derecho, la politología y la comunicación, lo que la autoriza especialmente para enmarcar la reflexión sobre nuestro tema. Luhmann continúa y lleva a su máxima expresión la lucha por el «viejo pensamiento europeo» iniciada por Nietzsche un siglo antes. Para ello se vale de su aparato estructural-funcional, con el que pretende minimizar la estructura comparando alternativas iguales (Izuzquiza Ortega, 1990: 101). En el fondo de su esquema subyace una obsesión por la igualdad y un odio a los prejuicios y valoraciones de la metafísica tradicional y la ontología clásica. La ciencia funcionaría como un código binario -todo puede ser verdad y no verdad-, verdadero motor (negativo) científico deconstructor que «disuelve los prejuicios ontológicos» (Luhmann, 1996: 144).

El valor de la verdad implica para Luhmann compromiso y adhesión, de ahí que lo positivo puede definirse por su capacidad de enlace. En el otro lado, el valor de no verdad, el polo negativo, se caracteriza por su valor reflexivo, simplificador, y aún podríamos decir, higienizador. De acuerdo con ello, podríamos entender lo negativo como una especie de «papelera de reciclaje» (Gil Villa, 2005:

7. En Nihilistas (F. GIL VILLA, 2009), he intentado desarrollar la idea de la socialización en el nihilismo utilizando como materiales las tradiciones mencionadas. 


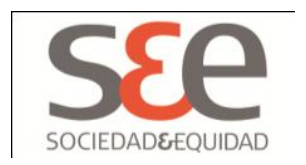

66). Ésta permitiría liberar el espacio, previniendo de la congestión institucional por ejemplo, administrativa y comunicacional, tan característica de nuestras sociedades (Giner, 2003). Encontramos aquí la primera conexión con el término de corrupción. En su aspecto físico, lo que se corrompe -o lo que se recicla- alude al movimiento negativo, destructivo, de un organismo que se descompone en una sopa de bacterias que retrotrae el sistema a su origen y permite su regeneración posterior. Por otro lado, el que la basura sea convertida en demonio y chivo expiatorio cultural de la burguesía occidental obsesionada por la higiene, abunda en su definición negativa. Paralelamente, el análisis del meta-relato que más inspira esa cultura, la tradición judeocristiana, lleva a la misma conclusión (Gil Villa, 2008: 22). El hombre y la mujer son corruptos por naturaleza, lo que atestigua el pecado original, la apropiación de un bien simbólico destinado a otro generalizado, en el mito del génesis, pero también la historia típica de la vanidad analizada en el Eclesiastés o en el Salmos: «todos se han descarriado y a una se han corrompido, no hay ni uno que haga el bien» (Sal 14, 2). La lección de la intersección entre el concepto físico y el mítico de la corrupción, es, pues, doble: que la corrupción es algo normal, como ya quedó dicho, y además, algo necesariamente negativo para que se convierta en positivo. Del detritus orgánico emergen las imágenes biológicas vegetales más gigantescas; el pecado y la muerte, y la consecuente corrupción del cuerpo, son la bases necesarias para la resurrección de la vida eterna y la redención.

Ahora bien, si como se encarga de recordarnos Luhmann, psicológicamente no es lo mismo asumir la verdad que la no verdad, debe implementarse una estrategia de comunicación en la que el término negativo elimine su lado peyorativo. La sustitución de la mentira por la no verdad es una muestra más de la aplicación de las tareas de la vigilancia epistemológica que se cuelan -ese es uno de los significados del concepto de reflexividad- de la ciencia en la vida cotidiana, y que son una prueba más de la tendencia cultural a la evaluación constante de todos los procesos de comunicación y de acción social, lo que a su vez es un reflejo del panorama final negativista.

Se trata de una estrategia porque, al pensar en términos de verdad y no verdad, el componente negativo resalta su lado positivo mostrando su complejidad, la cual equipara el Bien al Mal como referencias últimas de la energía que se retroalimentan: uno no tiene sentido sin el otro. Esa es la base del esquema funcionalista crítico. La presunción subyacente es que tanto la verdad como la no verdad están hechas de la misma materia, lo cual se observa, en un plano referencial, en los relatos de donde extraen sus bases éticas las conductas 


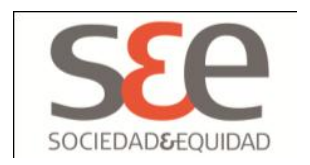

sociales. El ingrediente final y único es el "bueno", dado que, finalmente, El Maligno, versión del polo negativo, es tan sólo un ángel más, si bien rebelde.

Por otra parte, la mentira o no verdad como elemento negativo es más necesaria para el funcionamiento de los sistemas complejos, típicos de las últimas fases de la modernidad -individuos o sociedades- porque en su ausencia o su defecto la comunicación perdería eficacia. Se gastaría demasiado tiempo en justificaciones de todo tipo, necesarias para disminuir la anomia que salta al aumentar la división social del trabajo llevada a un extremo que probablemente supere lo que Durkheim imaginó (Durkheim, 1999); 0, en términos más psicológicos, para resolver las tensiones provocadas por las solidaridades cruzadas que imponen tantos y tan diversos roles sociales ejecutados por el sujeto medio. En cualquier caso, el corpus fenomenológico, la realidad que damos por sentado en la comunicación, crece y se desplaza a medida que avanza la modernidad y se desacralizan la ciencia y la cultura. El motivo central del uso de la mentira -o de la no verdad-, ya no es evitar el coste social que supone en términos de etiquetado, sino facilitar el tránsito de la trayectoria biográfica por las estructuras sociales en pos de un aumento de auto-realización, de acumulación de experiencias diferenciadoras, cuyo valor es neutro al valorarse positivamente aquellas que tienen signo negativo. Es así como racionalizamos el sufrimiento, en una aplicación del refrán, lo que no te mata te hace más fuerte. «No conozco un absurdo mayor declara a este respecto uno de los fundadores de la filosofía negativa modernaque el de la mayoría de los sistemas metafísicos, que declaran el mal como algo negativo, mientras que es precisamente lo positivo, lo que hace ello mismo perceptible; en cambio, el bien, esto es, toda felicidad y satisfacción, es lo negativo, a saber, la mera supresión de un deseo o finalización de un dolor» (Schopenhauer, 2009: 801).

Las consideraciones precedentes sirven para delinear el esquema cultural sobre el que debemos colocar la corrupción para comprender las raíces más profundas de su genealogía. El ciudadano sabe que la corrupción es el estado social normal, aunque los mensajes que emiten los creadores autorizados de opinión digan lo contrario. Igual que podemos definir el nihilismo normalizado como un estado donde se siente «vergüenza de uno mismo, como si uno se hubiera mentido a sí mismo demasiado tiempo» (Nietzsche, 1994: 34-35); así también el ciudadano parece pensar: «no nos engañemos, la corrupción está en todas partes». Con ello, desafía los intentos de canalización y focalización del concepto realizados por gobernantes y expertos, con la ayuda de los periodistas, su estrategia de circunscripción al ámbito de lo público, de lo sucesos extraordinarios y de lo económico, con la que se genera un extrañamiento de la experiencia, un 


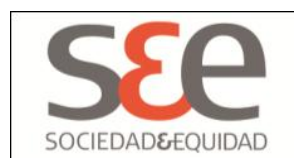

distanciamiento de la vida cotidiana. Sucede entonces que los prejuicios están más del lado de la versión oficial que de la intuida por la ciudadanía, algo que invierte la vieja idea heredada de los ilustrados según la cual las creencias del pueblo están cargadas de fantasmas irracionales, frente a la razón objetiva de los científicos y de los políticos.

\section{Corrupción y ruptura pacífica de la norma}

¿Cómo se oponen estas dos concepciones de la corrupción? ¿En qué términos se realiza el enfrentamiento? En el terreno de lo simbólico, como podemos comprobar analizando el papel que juega el tratamiento popular del tema en el humor cotidiano. «¿Sabe usted por qué los mexicanos no somos campeones en corrupción, sino subcampeones? Porque nos han pagado para ocupar el segundo puesto». Chistes como este forman parte del infinito repertorio al que debe sumarse la ironía y otros recursos similares. Armado con estos aparatos el ciudadano realiza, en un plano simbólico y siguiendo su intuición, marcada por la conexión con la socialización en el nihilismo y en la cultura del negativismo -entendida en la línea aquí sugerida-, una operación de inversión conceptual, dando la vuelta a la versión oficial y extrayendo lo positivo de lo negativo.

El tratamiento humorístico de la corrupción no debe interpretarse como un instrumento de aprendizaje del cinismo, sino como un modo de eludir la censura de la autoridad externa que marca lo políticamente correcto. Si nos servimos de las distinciones clásicas y más básicas hechas por Freud (2000: 117), observaremos que las técnicas del chiste sobre corrupción encajarían más en la remoción de un obstáculo externo que en la de un sentimiento íntimo, puesto que el ciudadano ha sido socializado en el uso de la no verdad. De esta forma, el chiste no sólo no esconde el cinismo del ciudadano, sino que sirve para denunciar el cinismo del poder sin coste alguno, es decir, emplazando el enfrentamiento en un terreno políticamente neutral, vale decir, sin signo, donde se anula la tensión.

De ahí que podamos establecer otra analogía en el modelo interpretativo de Freud, en el punto en el que adscribe al chiste un ahorro de gasto psíquico (Ibíd.: 118). Porque podríamos decir que paralelamente, en el terreno de lo social, el humor sobre la corrupción ahorra también energía, el gasto de la tensión directa al que podría llevar el enfrentamiento con la clase política, responsable intelectual de su dramática responsabilidad material en los escándalos de corrupción. Los gobernantes habrían utilizado la lucha contra la corrupción como una especie de cortina de humo para eludir la lucha contra la desigualdad social, su verdadera misión. La corrupción se convertiría así en uno de los chivos expiatorios favoritos 


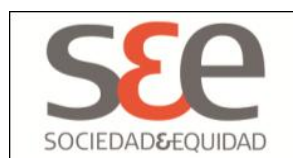

de la clase política democrática. A través del chiste, el ciudadano sustituiría el sufrimiento (del enfrentamiento político) por el principio del placer.

El análisis social debe insistir, en este punto, en que no se trata de una disyuntiva únicamente filosófica, sino política, aunque la relación entre las dos deba ser observada. No se juzga solamente la felicidad, sino el poder, con su referencia ineludible a la violencia.

La cultura de la corrupción en México en la alta modernidad podría cumplir de ese modo una función de nivelación social pacífica.

Una economía política de la corrupción debería pensarse -y juzgarse- por niveles, de acuerdo con los criterios típicos de las taxonomías administrativas. En los escalones inferiores es donde se desarrolla el mayor volumen de pequeños actos de corrupción privada. La sumatoria de esos egoísmos individuales neutraliza el aspecto negativo del acto. Si todos tomamos (robamos) una pequeña cantidad de algún bien destinado a otro generalizado, el daño causado se compensa dentro de ese nivel. Respecto a la repercusión del perjuicio en niveles superiores, dado el salto cualitativo, es tan insignificante que es despreciable.

En circunstancias de alta desigualad social, es decir, allí donde las políticas progresivas de distribución de la renta tienen escaso impacto -como en el caso de México-, la neutralización del aspecto antiético de la corrupción aumenta. De hecho, incluso podría aludirse, dentro de esta misma línea de argumentación, a su carácter revolucionario. Octavio Paz señalaba el ocaso del pensamiento revolucionario como un rasgo que definiría nuestra época (Paz, 1990: 6-7). En ella, la teoría ya no aspira a ofrecernos una cosmovisión coherente ni a elaborar «estrategias de mejora» que puedan inspirar políticas sociales (Bauman, 1988: 232).

Sin embargo, puede que el concepto de revolución siga vivo. Tal vez sólo se ha metamorfoseado en el contexto de pluralismo y relativismo cultural, de forma tal que se ha fragmentado en silenciosas micro-revoluciones, cuya carga cambia de sentido. De explosivas, pasarían ahora a ser implosivas. Instituciones como la corrupción cobrarían un nuevo significado a la luz de esta perspectiva. Nacidas bajo el signo de lo negativo, serían compatibles con la tendencia historiográfica a largo plazo de la pacificación de las sociedades modernas iniciada en el Renacimiento (Elias, 1993). De hecho, la función de la corrupción no sería exactamente la de corregir desequilibrios sociales, en cuyo caso tendría un carácter positivo, sino la de impedir que la desigualdad se desborde más allá de un 


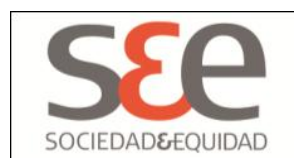

límite insostenible o intolerable para la convivencia, de tal forma, que no deje otra alternativa que la violencia social.

\section{Conclusiones}

Con todo, esta nueva forma de observar la corrupción, la sitúa dentro del universo de la ruptura de normas, lo cual sigue siendo coherente, de otra manera, con su carácter negativo. Desde este punto de vista, la corrupción es un acto de rebeldía contra un sistema legal que legitima una estructura social desigual. Pero se trata de un acto pacífico, cuya dimensión de violencia simbólica debe ser analizada si se quiere comprender en profundidad, tal y como se ha hecho aquí, de forma tentativa, con la referencia al humor popular. En lugares donde el Estado de derecho sólo se cumple medianamente en la práctica, instituciones como la corrupción dotan a la economía informal de complementos éticos y sociales destinados a paliar ese déficit. Para ello, la ciudadanía deconstruye los mensajes de los creadores oficiales de opinión, con la ayuda indirecta de las tendencias culturales profundas en las que ha sido socializada. La comunicación se procesa, se limpia del cinismo, invierte el contenido, transforma su conclusión catastrofista, negativa y frustrante, en fuente de placer a través del humor -el lado festivo de la revolución-, asumiendo el lado positivo de su carácter negativo pero respetando este último en lo que tiene de instrumento de rebeldía política.

Es posible mantener quizás, como aquí se ha hecho, que el tratamiento de la información sobre la corrupción por parte de políticos, intelectuales y medios de comunicación converge en un mensaje-noticia negativo: México está enfermo de corrupción. Mucho más que sus vecinos. Al mismo tiempo, la clase política es incapaz de reformarse, ofreciendo ejemplos continuos de prácticas corruptas, si bien tímidamente se va dotando administrativamente de nuevos recursos en la lucha contra la corrupción. Esta ambivalencia puede ser observada con arreglo al esquema cultural religioso católico. La corrupción sería como el pecado, un pecado más; de hecho, el pecado original que recuerda que la carne -y la voluntad- se corrompe, es decir, se pervierte, corre la tentación constante de alejarse de la actitud de honestidad y solidaridad con los demás reflejada en el cuidado de la cosa pública. Pero precisamente por eso es posible luchar contra la tentación del pecado (de la corrupción) cada día.

La corrupción no es un problema que se solucione nunca del todo absolutamente. El hecho de que que casi todos las practiquen en cosas grandes o pequeñas no debe llevarnos a una conclusión pesimista, como en la comparación con la teología, la naturaleza pecaminosa no desemboca lógicamente en una interpretación positiva o negativa -aunque obviamente, las lecturas demagógicas 


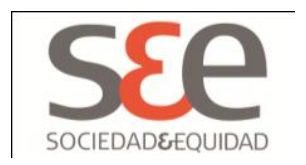

favorecen el catastrofismo y la pedagogía traumática, como hemos visto-. En clave cristiana, lo negativo, el pecado, es necesario, paradójicamente, para perfeccionar nuestra forma de ser; es un medio que potencia la resiliencia. Lo importante es que para lograrlo hay que arbitrar todo un conjunto de estrategias. Hay que vigilar constantemente la tendencia del pecado a colarse en cada acción. Lo mismo, mutatis mutandi, valdría para extraer conclusiones sobre la corrupción en un esquema de reflexión arreligioso pero realista. El hecho de que la corrupción sea una constante histórica y universal en primer lugar, unido al hecho de que está arraigada culturalmente, no implica sino que es un obstáculo "humano, demasiado humano".

Al igual que el trato con el medio ambiente, el sexo o la raza diferente, se trata de una asignatura pendiente. En materia de derechos fundamentales, nunca se puede bajar la guardia. En segundo lugar, si se quiere que la suma de miles de pequeñas victorias diarias contra la corrupción vivida en todos los terrenos sea superior a la suma de miles de pequeñas derrotas, se debería aumentar el número de estrategias en la lucha. Es más, se necesita en estos momentos, en México y en muchos otros lugares, educar primeramente en la conciencia de la corrupción. Es necesario hacer una pedagogía social que identifique la corrupción en toda su extensa gama de personajes y en niveles que aparentemente no se contemplan en la opinión pública (por ejemplo, el propio terreno religioso, o el medioambiental, es decir, terrenos supuestamente opuestos al político en la visión romántica de la ciudadanía). Es necesario, primero, que el "enfermo" de corrupción, es decir, el ciudadano normal y corriente, admita su enfermedad, real o potencial, en vez de alejarla de sí y verla solamente en el terreno de los otros, sobre todo de los políticos. En segundo lugar, habría que racionalizar la materia de la corrupción como un cuerpo de estudio que permite ser atacado con múltiples estrategias, comenzando por las educativas, a través de dinámicas de grupo en las aulas desde los primeros años de educación formal.

Por último, y de acuerdo siempre con las premisas expuestas en este trabajo, tales estrategias no deberían tratar el tema de la corrupción con etiquetas negativas y traumáticas. Un enfermo crónico necesita aceptar su enfermedad para superarla, necesita saber que debe "convivir" con su enfermedad -la corrupción-, lo que supone, en cierto sentido, no odiarla absolutamente sino amarla relativamente. No debe sentir que tiene el mal en el cuerpo sino un cierto mal que progresivamente irá saliendo del mismo. Ni traumas ni medidas absolutas. Progresividad y modestia serían tal vez las actitudes que más atraerían la actitud final de la honestidad solidaria con la cosa pública, actitudes acordes con un enfoque realista de la corrupción como el que aquí se ha intentado reflejar. Tal vez ese sea uno de los 


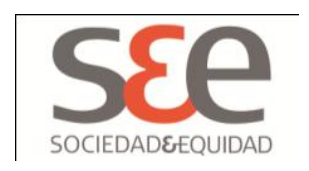

pocos caminos que aún podemos intentar para que la enfermedad social de la corrupción no acabe con nuestros valores más importantes.

\section{Referencias Bibliográficas}

Bauman, Z. (1988). «ls There a Postmodern Sociology?». Theory, Culture \& Society, vol. 5, n. ${ }^{\circ}$ 2-3: 217-238.

Dehesa, G. (2002). ¿Cómo nos arreglamos? Prontuario de la corrupción en México. México: Diana.

Durand Ponte, V.M. (2010). Desigualdad social y ciudadanía precaria. ¿Estado de excepción permanente?. México: Siglo XXI.

Durkheim, E. (1999). La división social del trabajo. $4^{\mathrm{a}}$ edición. México: Colofón.

Elias, N. (1993). El proceso de la civilización. Investigaciones sociogenéticas y psicogenéticas, México: FCE.

Freud, S. (2000). El chiste y su relación con lo inconsciente. Madrid: Alianza.

Germà Lluch, J.R. (2009). Cáncer. El fin de un mito. Barcelona: Planeta.

Gil Villa, F. (2005). «Autores amorales. Los peligros del pesimismo, parcialismo y simplismo en el análisis social». En, Alejandre, Gonzalo; Mora, Juan, y Pineda, Javier (eds.). Entre virajes y diluvios. La teoría y el método ante los dilemas de la sociedad global. México: UAM.

Gil Villa, F. (2008). La cultura de la corrupción. Madrid: Maia.

Gil Villa, F. (2007). La delincuencia y su circunstancia. Sociología del crimen y de la desviación, Valencia: Tirant lo Blanch.

Gil Villa, F. (2009). Nihilistas. La ilusión de vivir sin ilusiones. Madrid: Maia.

Giner, S. (2003). «Sociedad civil» En, Ariño Villaroya, Antonio (ed.). Diccionario de la Solidaridad (I), Valencia, Tirant lo Blanch, pp. 439-462.

Izuzquiza Otero, I. (1990). La sociedad sin hombres. Niklas Luhmann o la teoría como escándalo, Barcelona: Anthropos. 


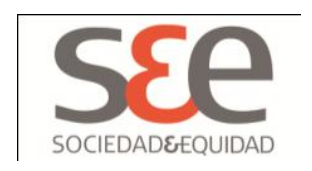

Krauze, E. (1996). Tiempo contado. México: Océano.

KPGM (2009). Encuesta de Fraude y Corrupción en México de 2008, México-DF. Disponible en: http://www.contraloriaciudadana.org.mx/mediciones/nacionales/10_KPMG_Encue nta_Fraude2008.pdf.

Luhmann, N. (1996). La ciencia de la sociedad. México: Antrhopos/UIA/ITESO.

Nietzsche, F. (1994). La voluntad de poderío. Madrid: Edaf.

OCDE (2011). “Income Inequality", in Society at a Glance 2011: Social Indicators, OCDE Publishing.

Paz, O. (1990). La otra voz. Poesía y fin de siglo. $2^{\mathrm{a}}$ edición, Barcelona: Seix Barral.

Reiner, R. (1997). «Media made criminality: the representation of crime in the mass media». En, Maguire, Mike; Morgan, Rod y Reiner, Robert (eds.). The Oxford Handbook of Criminology, Oxford, Oxford University Press, pp. 302-337.

SEDESOL (Secretaría de Desarrollo Social) (2010). Manual ciudadano 2010. MéxicoDF.

Schopenhauer, A. (2009). Parerga y Paralipómena. Madrid: Valdemar.

Sontaga, S. (2008). La enfermedad y sus metáforas: El sida y sus metáforas. Barcelona: Debolsillo.

Tomasini Bassols, A. (2009). Pena capital y otros ensayos. México: Icarus.

UNODC, (United Nations Office on Drugs and Crime) (2011). Global Study on Homocide. Vienna. 